\title{
Automatisch zum Kunden
}

Während in der Industrieproduktion Automatisierung ein alter Hut ist, wurde und wird im Marketing noch vieles „,on Hand gemacht“. Aber auch das ändert sich zurzeit. Neue Technologien ermöglichen es, Vorgänge zu automatisieren, für die man früher hochqualifizierte Spezialisten brauchte. Die Technik kann das inzwischen oft nicht nur genauso gut oder besser, sondern zudem weitaus schneller - und auch im Marketing gilt „Zeit ist Geld“.

Ein zentraler Aspekt dabei sind natürlich Daten. Noch nie wurden so viele Daten über Kunden gesammelt, wie heute. Ihren Wert erhalten Daten aber erst durch sinnvolle und zielgerichtete Auswertung. Kompetenzen im Bereich Data Science sind deshalb so wichtig. Es gibt bereits von künstlicher Intelligenz getriebene Marketingprozesse - aktuell ist die Realität in vielen Unternehmen aber in der Regel noch analog. Das bedeutet, dass die Organisation die Digitalisierung des Marketings noch lernen muss. Werkzeuge, mit denen man ganze Omnichannel-Kampagnen automatisiert durchführen kann, gibt es in großer Zahl am Markt - das richtige zu finden, erfordert aber spezielle Kenntnisse.

Im Zentrum des ganzen Aufwandes steht natürlich der Mensch als Kunde. Wie entscheidet dieser? Welche Rolle spielt der Preis? Die Wissenschaft von sogenannten Behavioral Patterns - von Verhaltensmustern also - bietet da einige Antworten. Vollständig automatisiert wird das Marketing aber wohl nie sein, meint Philipp Spreer, Berater und Konzepter bei elaboratum im Interview und meint, dass die kommenden Jahre für Marketer zu den spannendsten in ihrem Berufsleben zählen könnten. Er rät aber dringend dazu, sich jetzt mit den kreativ-konzeptionellen Aspekten von Marketing und natürlich vor allem Behavioral Sciences zu beschäftigen.

Ich wünsche Ihnen eine spannende Lektüre

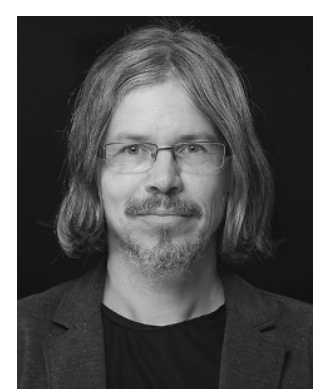

Peter Pagel $(\bowtie)$

peter.pagel@springer.com

Wiesbaden, Deutschland

Peter Pagel

Chefredakteur

Wirtschaftsinformatik \& Management 2021 • 13 (4): 251 https://doi.org/10.1365/s35764-021-00353-8

Angenommen: 14. Juli 2021

Online publiziert: 15. Juli 2021

(c) Springer Fachmedien Wiesbaden GmbH, ein Teil von Springer Nature 2021 